\title{
Study on the Status of Health Service Utilization among 3-5 Years Old Left-Behind Children in Poor Rural Areas of Hunan Province, China: A Cross-Sectional Survey
}

\author{
Yufeng Ouyang ${ }^{1,+}{ }^{+}$Jiaojiao Zou ${ }^{1, \dagger}$, Meimei Ji ${ }^{2}$, Yefu Zhang ${ }^{2}$, Tong Yuan ${ }^{2}$, Lina Yang ${ }^{1, *}$ and \\ Qian Lin ${ }^{1, *(1)}$ \\ 1 Department of Nutrition Science and Food Hygiene, Xiangya School of Public Health, Central South \\ University, 110 Xiangya Road, Changsha 410078, China; ouyangyufeng0102@foxmall.com or \\ oyyf0102@csu.edu.cn (Y.O.); zjj170605@foxmail.com or zjj227@csu.edu.cn (J.Z.) \\ 2 Department of Nutrition Science and Food Hygiene, Xiangya School of Public Health, \\ Central South University, 110 Xiangya Road, Changsha 410078, China; jimeimei1024@foxmail.com (M.J.); \\ yefuzhang@foxmail.com (Y.Z.); yuantong168@foxmali.com (T.Y.) \\ * Correspondence: ylnly1997@csu.edu.cn (L.Y.); linqian@csu.edu.cn (Q.L.); Tel.: +86-0731-84135414 (Q.L.) \\ + These authors contributed equally to this paper.
}

Received: 30 November 2018; Accepted: 28 December 2018; Published: 4 January 2019

\begin{abstract}
The left-behind children (LBC) in China generally refer to children who remain in rural regions under the care of kin members while their parents migrate to urban areas. Due to some reasons, e.g., poverty, poor transportation conditions, lack of health resources, and preschool child care, it is hard for preschool-aged rural LBC to obtain essential health services. Random cluster sampling was used to recruit the caregivers and all the 3-5-year-old LBC in two rural counties in Hunan Province. A questionnaire was used to collect data on LBC demographics via face-to-face interviews with the caregivers. Health service needs were evaluated by the two-week prevalence rate, while health service utilization was measured by the two-week physician visit rate. Of the 559 respondents in the study, the two-week prevalence rate was $44.2 \%$ and the two-week physician visits rate was $48.6 \%$. Nearly half of the sick children did not go to a hospital, $45.7 \%$ self-treated, and $5.3 \%$ did not take any treatment. The utilization rates of "health check," "eye exam," and "hearing screening for 3-year-olds" were extremely low (57.3\%, 29.3\%, 18.7\%). The utilization rate of health services for preschool LBC in poor rural areas was extremely low, which can affect the normal growth and development of children.
\end{abstract}

Keywords: Left-behind children; health service utilization; caregiver; rural area; China

\section{Introduction}

In China, the construction of medical and health service systems has been progressing steadily. However, the progress of basic health services for children still includes imbalances between rural and urban areas [1]. A national survey in 2013 showed the two-week prevalence rate among children under 5 years in rural areas of central China was $10.3 \%$, and the two-week physician visit rate was $12.8 \%$, lower than the rate in urban areas (14.6\%) [2]. Poverty, poor transportation conditions, and a lack of health resources leads to significant barriers to health service access among local children, especially for left-behind children (LBC).

The LBC in China generally refer to children who remain in rural regions under the care of kin members while their parents migrate to urban areas, usually for economic reasons [3]. In many cases, 
these children are taken care of by their grandparents. In 2013, China had 61.025 million LBC in rural areas, including 23.42 million children aged $0-5$ years. The proportion of the $0-5$-year-old children was $38.37 \%$ of all rural children, having increased by $47.73 \%$ compared to 2005 [4]. Without parental care and preschool child care institutions, it is hard for preschool-aged rural LBC to obtain essential health services. During early childhood, humans develop more rapidly than at any other point in their life. At this time, preventative healthcare is easier. However, limited health service resources may result in missing out on the best prevention and treatment period for these diseases among rural LBC. The preschool LBC in poor rural areas should receive more public health attention.

At present, in China, there are some studies on the utilization of health services for LBC in rural areas, but most of them focus on hospital services and childhood immunizations. A study indicated that the proportion of LBC receiving health checks in western rural areas was only $48.2 \%$ [5], far lower than the average level in China (83.1\%) [6]. There are few reports on the utilization of public health services, such as vision and hearing screenings, in rural areas and urban areas.

This baseline study selected Pingjiang County and Fenghuang County in Hunan Province to investigate the health service needs and the health service utilization of rural preschool LBC and explore relevant factors. These counties are both nationally designated as poor and having a high LBC population [7]. Pingjiang County is mainly hilly with the permanent population of Han majority [8]. Fenghuang County is located in the mountainous area with complex topography; the overall economic situation is worse than Pingjiang County. Fenghuang county's ethnic minorities account for $78.9 \%$ of the resident population, mainly Tujia and Hmong [9]. This study aims to inform future health policy for LBC in poor rural areas.

\section{Materials and Methods}

This study was conducted as part of a baseline survey of "The impact of conditional cash transfer on the nutritional status and physical development of 3-5-year-old LBC in poor rural areas of China" [7].

\subsection{Research Setting}

Hunan Province, located in south-central China, has a population where more than half of the rural children are LBC. Fenghuang County in Xiangxi Tujia and Miao Autonomous Prefecture and Pingjiang County in Yueyang City were chosen as the settings for this research project, which represent a range of geographies for this project [7].

\subsection{Sampling}

Village inclusion criteria: Villages were included if they had a minimum of 15 LBC (aged 3-5 years old) living in poor households, defined as annual income $<2300$ Renminbi (RMB, Chinese currency, $1 \mathrm{RMB}=0.145$ USD), had no kindergarten or care centers for LBC, and did not receive any funding or benefits from other sources, such as charities or non-governmental organizations (NGOs).

Participant inclusion criteria: All the 3-5-years-old LBC and their caregivers in the selected villages were eligible. Eligibility criteria for households in the intervention villages were as follows: (1) Households caring for at least one LBC (3-5 years old); (2) "poor households," defined as average per-capita annual income lower than 2300 RMB; (3) households did not receive benefits from other charities, NGOs (Non-Governmental Organizations), or other similar programs.

In this study, villages were used as the basic units for grouping. The local health departments of Fenghuang County and Pingjiang County assisted us in the random selection of villages. The baseline measurements, including anthropometric measures and blood tests, were performed for all eligible LBC whose caregivers consented in the 40 selected villages before randomisation. The random allocation sequence was produced by an independent statistician who was not involved in the study. Additionally, the allocation considered the distance between villages to avoid contamination. If two 
villages were found to be too close to each other $(<5 \mathrm{~km})$, the random sequences would be generated and grouped again [7].

Eventually, 132 villages in Fenghuang County and 72 villages in Pingjiang County met the inclusion criteria of this study. Each County randomly selected 20 villages, and each village randomly selected 15 LBC who met the inclusion criteria.

\subsection{Recruitment}

As we described in a previous article [7], eligible caregivers were identified with the assistance of a local village doctor. Phone calls were used to notify the caregivers to participate in the questionnaire surveys in village clinics, 1-2 weeks in advance of the investigation. Travel expenses (60 RMB, about 9 USD) were reimbursed for each caregiver. Individuals were free to ask questions following the explanation or quit the investigation at any time.

\subsection{Ethical Approval}

This research was approved by the independent ethics committee of the Institute of Clinical Pharmacology, Central South University (registered number: ctxy-140003) and registered in the China Clinical Trial Register (registered number: ChiCTR-TRC-14005117). Informed consents were obtained by caregivers and all information was kept strictly confidential.

\subsection{Data Collection}

Face-to-face interviews were used to collect information. Investigators were the village doctors or health staff from township hospitals. Each investigator was trained by nutrition and public health researchers from Central South University. Quality control and guidance personnel were present during the interview process and a trained director conducted further validity checks in order to guarantee the accuracy of the final completed questionnaires.

The baseline investigation was carried out between January and March 2015. Data collection included: (1) General characteristics of LBC and their caregivers; (2) LBC's health status and health service utilization. The two-week prevalence rate was used to reflect health service needs, while the two-week visiting rate and participation in basic public health services were used to evaluate health service utilization. Immunization coverage and rates of vision screening, hearing screening, and growth monitoring were used to evaluate the utilization of primary public health services. We conducted questionnaire interviews with caregivers and compared children's immunization certificates to obtain a realistic appraisal of local LBC's childhood immunization situation. The rates of vision screening and hearing screening were self-reported by caregivers.

\subsection{Statistical Analysis}

EpiData 3.0 software (The EpiData Association, Odense, Denmark) was used for data entry and the IBM SPSS 18.0 software package (IBM Corp, Armonk, NY, USA) was used for data analysis. The statistical methods used in this research include statistical descriptions and chi-squared tests. Descriptive data were reported in the form of a percentage and $p \leq 0.05$ was considered to be statistically significant.

\section{Results}

\subsection{General Characteristics of Study Population}

The socio-demographic characteristics of the study population are presented in Table 1. Of the 559 respondents in this study, most of the participants were ethnic minorities (75.5\%) in Fenghuang County, while the majority of the participants were Han ethnicity (98.3\%) in Pingjiang County. A comfortable majority of these children $(69.3 \%)$ had siblings. The proportion of premature and 
low birthweight children in the two counties was $8.0 \%$ and $4.0 \%$, respectively. Most of the LBC were left behind by their parents $(75.3 \%)$.

Table 1. Socio-demographic characteristics of left-behind children $(n, \%)(n=559)$.

\begin{tabular}{|c|c|c|c|}
\hline \multirow{2}{*}{ Characteristics } & \multirow{2}{*}{ Fenghuang County ( $n=273$ ) } & \multirow{2}{*}{ Pingjiang County $(n=286)$} & \multirow{2}{*}{$\begin{array}{c}\text { Total } \\
(n=559)\end{array}$} \\
\hline & & & \\
\hline \multicolumn{4}{|l|}{ Age (year) } \\
\hline $3 \sim$ & $87(31.9 \%)$ & $88(30.8 \%)$ & $175(31.3 \%)$ \\
\hline $4 \sim$ & $89(32.6 \%)$ & $90(31.4 \%)$ & $179(32.0 \%)$ \\
\hline $5 \sim$ & $97(35.5 \%)$ & $108(37.8 \%)$ & $205(36.7 \%)$ \\
\hline \multicolumn{4}{|l|}{ Sex } \\
\hline Male & $153(56.0 \%)$ & $144(50.3 \%)$ & $297(53.1 \%)$ \\
\hline Female & $120(44.0 \%)$ & $142(49.7 \%)$ & $262(46.9 \%)$ \\
\hline \multicolumn{4}{|l|}{ Ethnicity } \\
\hline Han & $67(24.5 \%)$ & $281(98.3 \%)$ & $348(62.3 \%)$ \\
\hline Minorities & $206(75.5 \%)$ & $5(1.7 \%)$ & $211(37.7 \%)$ \\
\hline The only child ${ }^{\#}$ & $57(24.6 \%)$ & $93(36.3 \%)$ & $150(30.7 \%)$ \\
\hline Premature ${ }^{\#}$ & $15(6.9 \%)$ & $22(8.9 \%)$ & $37(8.0 \%)$ \\
\hline Low birth weight $(<2500 \mathrm{~g}){ }^{\#}$ & $7(2.7 \%)$ & $9(4.2 \%)$ & $16(4.0 \%)$ \\
\hline \multicolumn{4}{|l|}{ Breast feeding $\#$} \\
\hline No & $45(20.2 \%)$ & 77 (31.2\%) & $122(26.0 \%)$ \\
\hline Yes (<6 months) & $9(4.0 \%)$ & $23(9.3 \%)$ & $32(6.8 \%)$ \\
\hline Yes ( $\geq 6$ months) & $169(75.8)$ & 147 (59.5\%) & $316(67.2 \%)$ \\
\hline \multicolumn{4}{|l|}{ Left-behind situation } \\
\hline Father away & $69(25.3 \%)$ & $42(14.7 \%)$ & $111(19.9 \%)$ \\
\hline Mother away & $14(5.1 \%)$ & $13(4.5 \%)$ & $27(4.8 \%)$ \\
\hline Both parents away & $190(69.6 \%)$ & $231(80.8 \%)$ & $421(75.3 \%)$ \\
\hline
\end{tabular}

" Missing data for baseline investigation.

\subsection{Health Service Needs}

As shown in Table 2, the two-week prevalence rate was 44.2\% (246/556). Fever/headache/cough caused by respiratory tract infection accounted for $68.0 \%$, while abdominal pain and diarrhea caused by gastrointestinal infection accounted for $13.3 \%$. Among ill LBC, $13.0 \%$ of them experienced symptoms twice or more. The two-week physician visits rate was $48.6 \%$. Most of the ill children were treated in village clinics (52.9\%, Table 3). As shown in Figure 1, 45.7\% of the sick children did not go to the doctor and instead were self-treated, and $5.3 \%$ of them did not take any treatment. Most caregivers reported "they think hospital treatment is useless" (34.1\%) or "too far away from the hospital" (34.1\%) as the main reasons for why LBC did not see a doctor (Figure 2). In our study, sick children who lived less than $15 \mathrm{~min}$ from the nearest medical institution were more likely to visit the hospital $(46.6 \% \mathrm{vs}$. $34.1 \%, p<0.05)$.

Table 2. Health situation and health service needs among left-behind children $(n, \%)(n=246)$.

\begin{tabular}{|c|c|c|c|}
\hline Variables & Fenghuang County $(n=112)$ & Pingjiang County $(n=134)$ & Total $(n=246)$ \\
\hline Two-week prevalence $\#$ & $112(41.2 \%)$ & $134(47.2 \%)$ & $246(44.2 \%)$ \\
\hline Two-week physician visiting \#,** & $39(34.8 \%)$ & $80(60.2 \%)$ & $119(48.6 \%)$ \\
\hline \multicolumn{4}{|l|}{ Presenting symptoms(man-time) \# } \\
\hline Fever/Headache/Cough & $93(76.2 \%)$ & $96(61.5 \%)$ & $189(68.0 \%)$ \\
\hline Abdominal pain/Diarrhea & $13(10.7 \%)$ & $24(15.4 \%)$ & $37(13.3 \%)$ \\
\hline $\begin{array}{c}\text { Chest } \\
\text { pain/Flustered/Palpitations }\end{array}$ & $1(0.8 \%)$ & $2(1.3 \%)$ & $3(1.1 \%)$ \\
\hline Trauma & $2(1.6 \%)$ & $1(0.6 \%)$ & $3(1.1 \%)$ \\
\hline Others & $13(10.7 \%)$ & $33(21.2 \%)$ & $48(16.5 \%)$ \\
\hline \multicolumn{4}{|l|}{ Types of symptoms \# } \\
\hline 1 & $102(91.9 \%)$ & $116(86.6 \%)$ & $218(89.0 \%)$ \\
\hline 2 & $8(7.2 \%)$ & $14(10.4 \%)$ & $22(9.0 \%)$ \\
\hline 3 and above & $1(0.9 \%)$ & $4(3.0 \%)$ & $5(2.0 \%)$ \\
\hline
\end{tabular}

Chi-square test, ${ }^{* *} p<0.01$; ${ }^{\#}$ Missing data for baseline investigation. 
Table 3. Visits to the hospitals at different levels $(n, \%)(n=119)$.

\begin{tabular}{cccccc}
\hline $\begin{array}{c}\text { Hospitals at } \\
\text { Different Levels }\end{array}$ & $\begin{array}{c}\text { Fenghuang County } \\
(\boldsymbol{n}=\mathbf{3 9 )}\end{array}$ & $\begin{array}{c}\text { Pingjiang County } \\
(\boldsymbol{n}=\mathbf{8 0})\end{array}$ & Total $(\boldsymbol{n = 1 1 9 )})$ & $\boldsymbol{\chi}^{\mathbf{2}}$ & $\boldsymbol{p}$ \\
\hline Village clinics & $15(38.5 \%)$ & $48(60.0 \%)$ & $63(52.9 \%)$ & & \\
Township hospitals & $15(38.5 \%)$ & $19(23.8 \%)$ & $34(28.6 \%)$ & & \\
County hospitals & $6(15.4 \%)$ & $7(8.8 \%)$ & $13(10.9 \%)$ & 7.611 & 0.107 \\
City hospitals and above & $3(7.7 \%)$ & $3(3.8 \%)$ & $6(5.0 \%)$ & & \\
others & $0(0.0 \%)$ & $3(3.8 \%)$ & $3(2.5 \%)$ & & \\
\hline
\end{tabular}

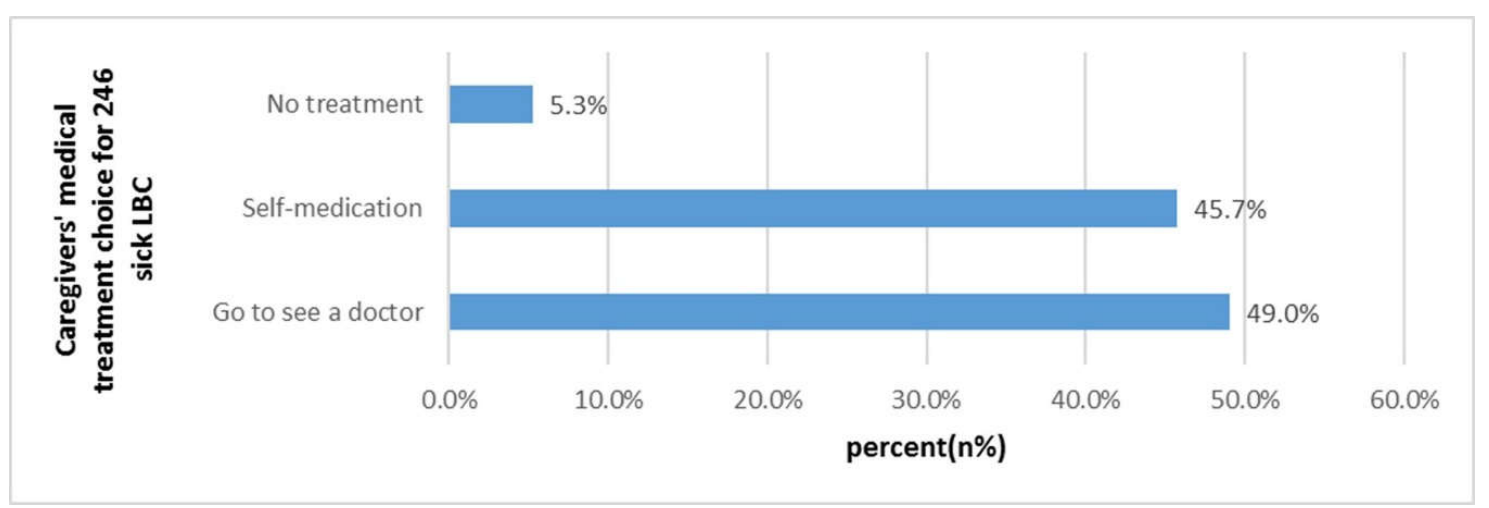

Figure 1. Caregivers' medical treatment choice for 246 sick LBC $(n, \%)$.

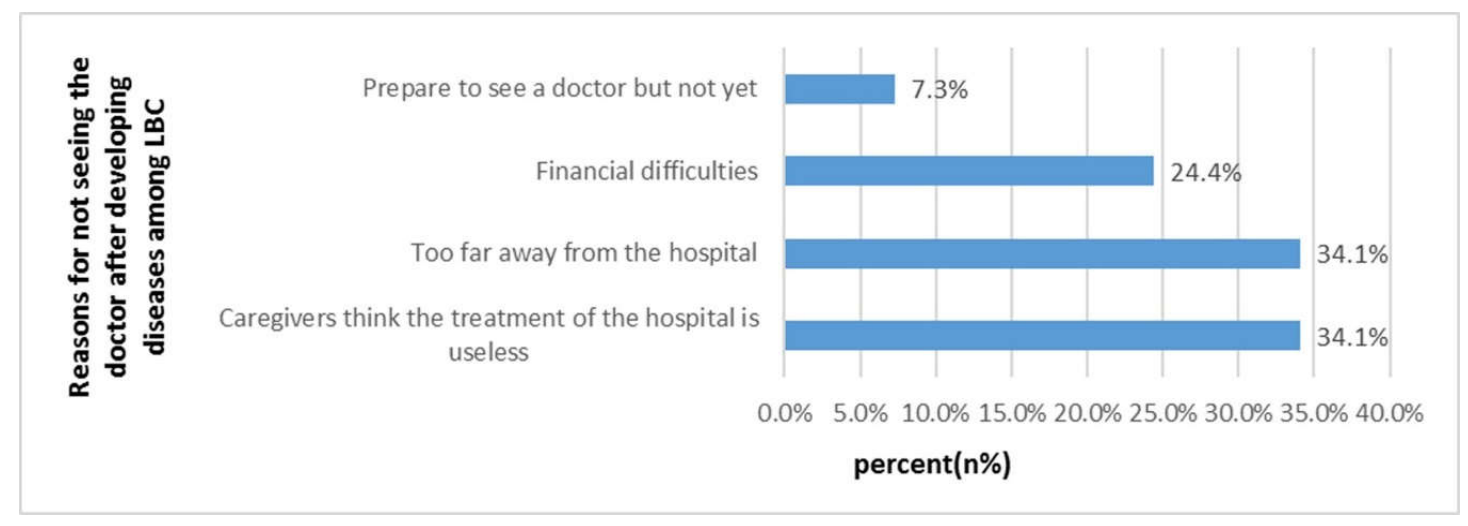

Figure 2. Reasons for why LBC did not see a doctor after developing diseases in the past two weeks $(n, \%)$.

\subsection{Health Services Utilization}

The utilization rates for "health check in 2014," "eye exam in 2014," and "hearing screening for 3-year-olds" were extremely low $(57.3 \%, 29.3 \%$, and $18.7 \%$, respectively) (Table 4$)$. The utilization rate among LBC of children's basic health service had a significant difference between the two counties. Table 5 shows the social demographic characteristics differences between the two counties, i.e., ethnicity, only child status, region, age of caregiver, and socioeconomic status on the utilization of health services for LBC had statistical difference significance $(p<0.001$, Table 5). According to Figure 3 , the main reason for why LBC did not use basic public health services was that "caregivers do not know about these public health services" (68.4\%). The two main "other reasons" were: "Town hospitals don't have the above health services and facilities" (22.2\%) and "time conflicts with children going to school" (13.9\%). In Chinese National Basic Public Health Services Norm 2013, a 3-6-year-old child can receive an annual free health check in local health institutions, included as a basic health care. As is shown in Table 6, awareness that "my child can receive annual free health checks in local health institutions" was low $(45.5 \%)$, and the awareness rate of Fenghuang County was lower than that of Pingjiang County $(30.7 \%$ vs. $59.4 \%, p<0.001)$. 
Table 4. Basic public health services among left-behind children $(n, \%)(n=557)$.

\begin{tabular}{|c|c|c|c|c|c|}
\hline Answer & $\begin{array}{l}\text { Fenghuang County } \\
(n=273)\end{array}$ & $\begin{array}{c}\text { Pingjiang County } \\
(n=284)\end{array}$ & Total $(n=557)$ & $x^{2}$ & $p$ \\
\hline \multicolumn{4}{|c|}{ Received the childhood immunization \# } & 5.328 & 0.070 \\
\hline yes & $263(98.1 \%)$ & $283(100.0 \%)$ & $546(99.1 \%)$ & & \\
\hline no & $1(0.4 \%)$ & $0(0.0 \%)$ & $1(0.2 \%)$ & & \\
\hline unclear & $4(1.5 \%)$ & $0(0.0 \%)$ & $4(0.7 \%)$ & & \\
\hline \multicolumn{4}{|c|}{ Received the child health handbook } & 226.046 & $<0.001$ \\
\hline yes & $40(4.7 \%)$ & $221(77.8 \%)$ & $261(46.9 \%)$ & & \\
\hline no & $144(52.7 \%)$ & $48(16.9 \%)$ & $192(34.5 \%)$ & & \\
\hline unclear & $89(32.6 \%)$ & $15(5.3 \%)$ & $104(16.7 \%)$ & & \\
\hline \multicolumn{4}{|c|}{ Received free health check in 2014} & 80.584 & $<0.001$ \\
\hline yes & $104(38.1 \%)$ & $215(75.7 \%)$ & $319(57.3 \%)$ & & \\
\hline no & $141(51.6 \%)$ & $58(20.4 \%)$ & $200(35.9 \%)$ & & \\
\hline unclear & $28(10.3 \%)$ & $20(7.0 \%)$ & $38(6.8 \%)$ & & \\
\hline \multicolumn{4}{|c|}{ Measured height and weight for free } & 85.696 & $<0.001$ \\
\hline yes & $92(33.7 \%)$ & $206(72.5 \%)$ & $298(53.5 \%)$ & & \\
\hline no & $147(53.8 \%)$ & $58(20.4 \%)$ & $205(36.8 \%)$ & & \\
\hline unclear & $34(12.5 \%)$ & $20(7.0 \%)$ & $54(9.7 \%)$ & & \\
\hline \multicolumn{4}{|c|}{ Received free eye exam in $2014^{\#}$} & 95.519 & $<0.001$ \\
\hline yes & $28(6.6 \%)$ & $135(47.5 \%)$ & $163(29.3 \%)$ & & \\
\hline no & $213(78.3 \%)$ & $121(42.6 \%)$ & $334(60.1 \%)$ & & \\
\hline unclear & $31(11.4 \%)$ & $28(9.9 \%)$ & $59(10.6 \%)$ & & \\
\hline \multicolumn{4}{|c|}{ Received hearing screening at 3 years old $\#$} & 57.001 & $<0.001$ \\
\hline yes & $18(6.6 \%)$ & $86(30.4 \%)$ & $104(18.7 \%)$ & & \\
\hline no & $219(80.5 \%)$ & $153(54.1 \%)$ & $372(67.0 \%)$ & & \\
\hline unclear & $35(12.9 \%)$ & $44(15.5 \%)$ & $79(14.2 \%)$ & & \\
\hline
\end{tabular}

\# Missing data for baseline investigation.

Table 5. Public health services for LBC with different social demographic characteristics ( $n, \%)$.

\begin{tabular}{|c|c|c|c|}
\hline Variables & Health Check in 2014 & Eye Exam in 2014 & $\begin{array}{l}\text { Hearing Screening for } \\
\text { 3-Year-Olds }\end{array}$ \\
\hline Total $(n=559)$ & $319(57.0 \%)$ & $163(29.2 \%)$ & $104(18.6 \%)$ \\
\hline \multicolumn{4}{|l|}{ LBC's characteristics } \\
\hline \multicolumn{4}{|l|}{ Age (year) } \\
\hline $3 \sim$ & $106(60.6 \%)$ & $59(33.7 \%)$ & $39(22.3 \%)$ \\
\hline $4 \sim$ & $99(55.9 \%)$ & $44(24.9 \%)$ & $30(17.0 \%)$ \\
\hline $5 \sim$ & $114(55.6 \%)$ & $60(29.4 \%)$ & $35(17.2 \%)$ \\
\hline \multicolumn{4}{|l|}{ Sex } \\
\hline Female & $164(55.2 \%)$ & $78(26.3 \%)$ & $48(16.2 \%)$ \\
\hline Male & $155(59.6 \%)$ & $85(32.8 \%)$ & $56(21.6 \%)$ \\
\hline \multicolumn{4}{|l|}{ Ethnicity } \\
\hline Han & $202(58.2 \%)$ & $107(30.8 \%)$ & $80(23.1 \%)$ \\
\hline Minorities & $117(55.7 \%)$ & $56(26.8 \%)$ & $24(11.5 \%)$ \\
\hline \multicolumn{4}{|l|}{ Only child ${ }^{\#}$} \\
\hline yes & $83(55.7 \%)$ & $43(28.9 \%)$ & $37(24.8 \%)^{* *}$ \\
\hline no & $196(58.2 \%)$ & $100(29.8 \%)$ & $53(15.8 \%)$ \\
\hline \multicolumn{4}{|l|}{ Left-behind situation } \\
\hline father work outside & $58(52.7 \%)$ & $31(28.2 \%)$ & $15(13.5 \%)$ \\
\hline mother work outside & $13(48.1 \%)$ & $7(25.9 \%)$ & $4(14.8 \%)$ \\
\hline parents work outside & $248(59.0 \%)$ & $125(29.8 \%)$ & $85(20.3 \%)$ \\
\hline
\end{tabular}


Table 5. Cont.

\begin{tabular}{|c|c|c|c|}
\hline Variables & Health Check in 2014 & Eye Exam in 2014 & $\begin{array}{l}\text { Hearing Screening for } \\
\text { 3-year-olds }\end{array}$ \\
\hline \multicolumn{4}{|l|}{ Caregiver's characteristics } \\
\hline \multicolumn{4}{|l|}{ Age (year) * } \\
\hline $20 \sim$ & $30(50.0 \%)$ & $16(26.7 \%)$ & $5(8.3 \%)$ \\
\hline $40 \sim$ & $155(59.2 \%)$ & $73(27.9 \%)$ & $46(17.6 \%)$ \\
\hline $60 \sim$ & $134(57.0 \%)$ & $74(31.6 \%)$ & $53(22.6 \%)$ \\
\hline \multicolumn{4}{|l|}{ Sex } \\
\hline female & $202(55.6 \%)$ & $104(28.7 \%)$ & $62(17.6 \%)$ \\
\hline male & $117(60.3 \%)$ & $59(30.4 \%)$ & $42(21.8 \%)$ \\
\hline \multicolumn{4}{|l|}{ Occupation } \\
\hline nonagricultural Worker & $37(58.7 \%)$ & $19(30.2 \%)$ & $12(19.0 \%)$ \\
\hline farmer & $282(57.1 \%)$ & $144(29.2 \%)$ & $92(18.4 \%)$ \\
\hline \multicolumn{4}{|l|}{ Education level } \\
\hline no formal education & $95(54.9 \%)$ & $50(29.1 \%)$ & $28(16.3 \%)$ \\
\hline primary school & $153(56.9 \%)$ & $77(28.5 \%)$ & $53(19.7 \%)$ \\
\hline junior middle school & $58(62.4 \%)$ & $31(33.3 \%)$ & $19(20.4 \%)$ \\
\hline high school and others & $13(61.9 \%)$ & $5(23.8 \%)$ & $4(19.0 \%)$ \\
\hline \multicolumn{4}{|l|}{ Relation to LBC } \\
\hline father/mother & $38(51.9 \%)$ & $24(32.4 \%)$ & $8(10.8 \%) *$ \\
\hline grandfather & $110(61.5 \%)$ & $59(33.0 \%)$ & $44(24.7 \%)$ \\
\hline grandmother & $164(56.0 \%)$ & $79(27.1 \%)$ & $51(17.5 \%)$ \\
\hline others & $7(63.6 \%)$ & $1(9.1 \%)$ & $1(9.1 \%)$ \\
\hline \multicolumn{4}{|l|}{ Areas } \\
\hline mountainous area & $156(57.4 \%)$ & $78(28.8 \%)$ & $33(12.2 \%) * *$ \\
\hline hilly area & $163(57.2 \%)$ & $85(29.8 \%)$ & $71(24.9 \%)$ \\
\hline \multicolumn{4}{|l|}{ Socioeconomic status \& } \\
\hline low & $83(60.8 \%)$ & $39(28.3 \%)$ & $15(10.9 \%)^{* *}$ \\
\hline middle & $162(57.9 \%)$ & $81(29.0 \%)$ & $54(19.4 \%)$ \\
\hline high & $74(53.2 \%)$ & $43(30.9 \%)$ & $35(25.2 \%)$ \\
\hline
\end{tabular}

Chi-square test, ${ }^{*} p<0.05,{ }^{* *} p<0.01$; ${ }^{\text {\& }}$ Socioeconomic status, which was estimated following principal component analysis, including various items related to the economic status (annual per capita income, housing type, access to tap water, number of children at home, and number of bedridden patients at home). \# Missing data for baseline investigation.

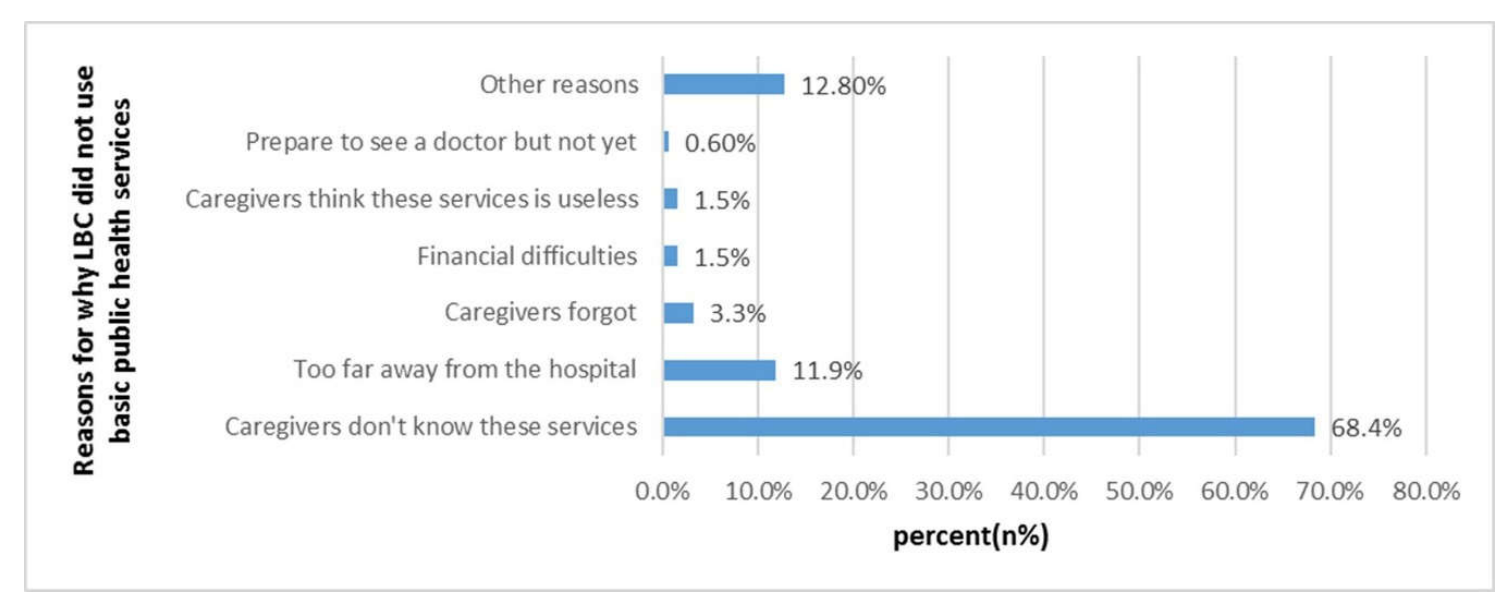

Figure 3. Reasons for why LBC did not use basic public health services $(n, \%)$. 
Table 6. Awareness of two public health services among left-behind children's caregivers $(n, \%)$ $(n=556)$.

\begin{tabular}{|c|c|c|c|}
\hline Awareness & $\begin{array}{c}\text { Fenghuang } \\
\text { County }(n=270)\end{array}$ & $\begin{array}{c}\text { Pingjiang } \\
\text { County }(n=286)\end{array}$ & Total $(n=556)$ \\
\hline Know children's planned immunization is free ** & $199(74.0 \%)$ & $251(88.4 \%)$ & $450(81.4 \%)$ \\
\hline $\begin{array}{l}\text { Know their child can receive free health check in } \\
\text { local health institutions }\end{array}$ & $83(30.7 \%)$ & $170(59.4 \%)$ & $253(45.5 \%)$ \\
\hline
\end{tabular}

\section{Discussion}

The baseline survey showed that the two-week prevalence rate among the LBC was $44.2 \%$ and the two-week physician visit rate was $48.6 \%$, which was higher than the average proportion of children under 5 in the rural areas of central China in 2013 (10.3\%, 12.8\%) [1]. It can be seen that the health state of LBC in rural areas is poor. We found that some of the LBC had meals near pig pens and dry toilets, and most of them did not wash their hand before meals or after using the toilet. More specialized child care facilities and preschool child care institutions are needed to provide a clean and safe environment for preschool. An Indonesian study found that unclean living conditions increased children's incidence of diarrhea [10]. Two interventions conducted in rural Bangladesh found that better living household hygiene decreased the children's incidence by $27 \%-30 \%$ [11-13].

We found that $52.9 \%$ of the LBC received medical treatment in the nearest township hospital. Among the sick children, the proportion of LBC who chose "self-treatment" was $49.0 \%$ and "no treatment measures" was 5.3\%, which were above the national average (14.1\% and $1.4 \%)$ [1]. "Caregivers thought the treatment in hospitals was ineffective" and "Inconvenient transportation" were the two main barriers to the health service utilization of LBC. Low-education levels may affect caregivers' ability to cultivate children scientifically and to access child health services [14-16]. When seeking health care in rural areas, people have to face the challenge of accessibility and high transportation cost [17]. Some studies have pointed out that "distance from medical institution" is one of the main obstacles to get health services for most residents in resource-limited environments (especially in rural areas with complex geographical locations) [18-23]. We found that "time to the nearest medical institution" has a significant impact on the "the two-week physician visit rate". Poor transportation conditions were the barriers for LBC receiving medical treatment and accessing health care services. A study in southern Tanzania found that infant and child mortality was higher among families living distances more than $5 \mathrm{~km}$ away compared to those living $<5 \mathrm{~km}$ from the nearest health facility [24]. Some studies also found that the distance from medical institutions and education levels are key factors affecting health care utilization in rural areas [25-27].

In China, the immunization certificate is a voucher for childhood immunization. It is also a must-have health certificate for children before entering school. In our study, the self-reported vaccination rate of LBC was above $98 \%$. Most caregivers had the awareness that "childhood immunization is provided by the government for free." It reflects that China has made great progress in childhood immunization, the most basic public health service. There are laws in China that mandate vaccination certificates for children, which ensures their statutory role and value. However, we found there were still some problems. For example, many caregivers did not realize the importance of the vaccination schedule, which has led to delayed vaccination or partly unvaccinated. We observed that the date of some LBC's immunization certificates was not accurate, the vaccination service period of the village clinic was not completely consistent with the national standard, and the vaccination services in the village clinic (including pre-examination, observation, notification) were not standardized, among others. The possible reasons and solutions are needed to explored in future studies.

At present, the emphasis on basic public health services for children is far from enough in China. We found that caregivers believed that the health service was important to children's health, but they did not know that children could receive these public health services for free (68.4\%). The current 
situation of public health services for children, such as children's vision and hearing screening, is rarely reported in rural areas or urban areas. Since 2011, the Chinese national basic public health service, including health check and eye exam, were provided free for children aged 0-6 years, and free hearing screening was also included since 2013.

Caregivers' health consciousness and their attention to different public health services will affect their utilization rate. The more they recognize the health service, the higher their utilization rate will be. We found the utilization of the rural LBC's public health services was poor. About $57 \%$ of the LBC received a "Health check" in 2014, including height and weight measurements, since most of the caregivers put more emphasis on children's anthropometric measurements. However, the rate of "Children's eye exam" and "Children's hearing screening" was low. In our field trips, most of the township hospitals lacked hearing screening equipment. In addition, compared to other public health services, "children's hearing screening" was most subject to time constraints and geographic conditions. Children can receive health checks or eye exams every year, but they can only receive hearing screening in a few fixed time periods. Hearing screenings cannot be performed effectively in time if the child is sick, the caregiver forgot, or it was inconvenient to visit township hospitals.

A primary care providing a vision or hearing screening is important for each child to receive further evaluation and necessary treatment. Amblyopia has become the most common visual disability in Chinese children. The prevalence rate of amblyopia in Chinese children was reported at $2.8 \%$ in 2016, with 6.16 million children aged 4-6 years [28]. Around 466 million people worldwide have a disabling hearing loss and 34 million of these are children [29]. At present, there are about 30,000 deaf children under the age of 7 in Hunan province, and they are increasing at an annual rate of about 1000. Among them, more than 8000 deaf children live in extremely poor families and generally lack basic rehabilitation and self-rescue ability [30]. The main causes of hearing loss in children are infections, such as mumps, meningitis, and chronic ear infections. Sixty percent of children's hearing loss can be prevented by vaccinating against infectious diseases, early hearing screening, and treating children with chronic ear infections [31]. Three to five years of age is a sensitive period for children's development, and it is also the best intervention time for vision and hearing impairment. Early detection and timely treatment are urgent for rural children.

The health status and the public health services of LBC in Fenghuang County were significantly worse than those in Pingiiang County. Fenghuang County is located in a mountainous area, with complex geographical features and inconvenient transportation. The health care knowledge of the caregivers in Fenghuang County was lower than that of Pingjiang County. Low education levels and language barriers were prominent in these caregivers: Some elderly Hmong caregivers could neither speak nor understand Mandarin, and only a few local medical staff could speak Miao language. Most of the Hmong LBCs were living in scattered areas that were difficult to centrally manage.

In summary, it is important to improve society's emphasis on the accessibility of health services for LBC in remote rural areas. The health system itself is a social determinant of health [30]. Health systems can reduce inequalities in access to health services through a variety of strategic policies that can benefit the most vulnerable groups due to personal, social, and geographic factors. A study in northern Brazil showed that adopting a primary health care strategy basically achieved health care equality in the Sobral region through the family health plan [32]. Therefore, the health sector can adopt some policy measures, such as incorporating vision and hearing screening into preschool health examinations; encouraging the establishment of hospital groups, medical complexes, and counterpart support so that community medical institutions can improve the service capacity for regular visits; and providing medical facilities and equipment for rural areas. On the other hand, the development of new medical models, such as telemedicine and mobile van services in the form of "charity mobile clinics", may improve the accessibility of children's health care services. In rural India, local community-based mobile health interventions (ImTeCHO, Gujarat, India) are adopted to expand the coverage of local health services [33]. Bangladesh has integrated the MCH (maternal and child health) handbook with mobile text messages and audio calls as a mobile health care tool for $\mathrm{MCH}$ services [34]. Accredited 
Social Health Activists (ASHAs), a new village-based front line of health workers, has been created in India for primary health care [33]. Improving the attractiveness of rural grassroots pediatric medical staff and increasing the number of qualified medical workers have proven to be effective solutions. Granting funds to poor and remote areas where LBC are prevalent and that lack child care institutions, building kindergartens, and centrally managing preschool LBC are also effective means.

This study reports for the first time the utilization of health services for preschool LBC in poor rural areas. The results of the study can provide a reference for further adjustment of health service strategies and policies for LBC in poor rural areas. However, there were some limitations in this study. Some subjective sensory indicators were used in the questionnaire, which may lead to a reporting bias and affect the results of the survey. Some older Hmong caregivers cannot understand Mandarin and needed translation assistance. During this process, the meaning of some of the items in the questionnaire may have been misinterpreted. Third, limited by terrain and human resources, small sample sizes may result in insignificant associations between variables, requiring further larger sample sizes. Fourth, since this survey was launched in 2014, we are referring to the 2013 edition of the National Basic Health Service Code. LBC exist based on China's unique societal context, and children's basic health services in different countries contain different items. Although we have discussed some international research, most of the results are based on Chinese data.

\section{Conclusions}

The utilization rate of health services for preschool LBC in poor rural areas was extremely low, which can affect the normal growth and development of children. We urgently need to take implement innovative strategies and public health educational programs to improve the utilization of health services for preschool LBC.

Author Contributions: Q.L. contributed to the conception and design of the study, drafted and revised the protocol and received grant for the study as the principle investigator; L.Y. was responsible for the conception and design of the section of health service utilization; J.Z., M.J., Y.Z., and T.Y. were participated in investigations and data collection. Y.O. and J.Z. wrote the first draft and final article versions of this paper. All authors interpreted the results and made a substantial contribution to the manuscript's improvement. All authors read the final manuscript and approved this submission.

Funding: This research was funded by the China Medical Board, grant number OC 13-157.

Acknowledgments: We thank the teachers and students from Xiangya School of Public Health, Central South University, in Changsha, China, for their help. We also gratefully acknowledge the China Medical Board for providing the grant for this project through the 2013 China Medical Board Open Competition Program. We also thank Joyce Wang (joycewang.701@gmail.com) for her help in language editing.

Conflicts of Interest: The authors declare no conflict of interest.

\section{Abbreviations}

The following abbreviations are used in this manuscript:

LBC Left-behind children

NGO Non-governmental organizations

\section{References}

1. Xu, L.; Meng, Q. The Fifth National Health Service Survey-Health services need, demand and utilization. Chin. J. Health Inform. Manag. 2014, 11, 193-194. (In Chinese)

2. Xinhua News Agency. The National Program for the Development of Children in Poor Areas (2014-2020). China Soc. Welf. 2015, 1, 58. (In Chinese)

3. Left-Behind Children in China. Available online: https://en.wikipedia.org/wiki/Left-behind_children_in_ China\#cite_ref-YELLOW_140 (accessed on 28 November 2018). 
4. Li, J.W.; Jing, L.; Xiong, Y. Current situation of utilization of health management services for children aged 0-6 years in rural areas and investigation and analysis of children's health problems. Chin. Gen. Pract. 2014, 17, 3590-3593. (In Chinese)

5. Wu, W. Study on the Health Service Utilization of Children Left-Behind in Western Rural Areas; Huazhong University of Science and Technology: Wuhan, China, 2013. (In Chinese)

6. All-China Women's Federation. Research Report on rural left-behind children and rural-urban migrant children in China. China Womens Mov. 2013, 6, 30-34. (In Chinese)

7. Lin, Q.; Adab, P.; Hemming, K.; Yang, L.; Qin, H.; Li, M.; Deng, J.; Shi, J.; Chen, J. Health allowance for improving the nutritional status and development of 3-5-year-old left-behind children in poor rural areas of china: Study protocol for a cluster randomised trial. Trials 2015, 16, 361. [CrossRef] [PubMed]

8. Pingjiang County. Available online: https://en.wikipedia.org/wiki/Pingjiang_County (accessed on 20 December 2018).

9. Fenghuang County. Available online: https://en.wikipedia.org/wiki/Fenghuang_County (accessed on 20 December 2018).

10. Gil, A.; Lanata, C.; Kleinau, E.; Penny, M. Children's Feces Disposal Practices in Developing Countries and Interventions to Prevent Diarrheal Diseases; A Literature Review; Strategic Report 11; Bureau for Global Health: Washington, DC, USA, 2004.

11. Alam, N.; Wojtyniak, B.; Henry, F.J.; Rahaman, M.M. Mothers' personal and domestic hygiene and diarrhoea incidence in young children in rural Bangladesh. Int. J. Epidemiol. 1989, 18, 242-247. [CrossRef] [PubMed]

12. Aziz, K.; Hoque, B.A.; Hasan, K.Z.; Patwary, M.; Huttly, S.R.; Rahaman, M.M.; Feachem, R.G. Reduction in diarrhoeal diseases in children in rural Bangladesh by environmental and behavioural modifications. Trans. R. Soc. Trop. Med. Hyg. 1990, 84, 433-438. [CrossRef]

13. Atuoye, K.N.; Dixon, J.; Rishworth, A.; Galaa, S.Z.; Boamah, S.A.; Luginaah, I. Can she make it? Transportation barriers to accessing maternal and child health care services in rural Ghana. BMC Health Serv. Res. 2015, 15, 333. [CrossRef]

14. Ji, M.; Zhang, Y.; Zou, J.; Yuan, T.; Tang, A.; Deng, J.; Yang, L.; Li, M.; Chen, J.; Qin, H.; et al. Study on the status of health service utilization among caregivers of left-behind children in poor rural areas of Hunan province: A baseline survey. Int. J. Environ. Res. Public Health 2017, 14, 910. [CrossRef]

15. Ogi, H.; Nakamura, D.; Ogawa, M.; Nakamura, T.; Izawa, K.P. Associations between Parents' Health Literacy and Sleeping Hours in Children: A Cross-Sectional Study. Healthcare 2018, 6, 32. [CrossRef]

16. Nakamura, D.; Ogawa, M.; Nakamura, T.; Izawa, K.P. Impact of Parents' Comprehensive Health Literacy on BMI in Children: A Multicenter Cross-Sectional Study in Japan. J. Sch. Health 2018, 88, 910-916. [CrossRef]

17. Treacy, L.; Bolkan, H.A.; Sagbakken, M. Distance, accessibility and costs. Decision-making during childbirth in rural sierra Leone: A qualitative study. PLoS ONE 2018, 13, e0188280. [CrossRef] [PubMed]

18. Gabrysch, S.; Campbell, O.M. Still too far to walk: Literature review of the determinants of delivery service use. BMC Pregnancy Childbirth 2009, 9, 34. [CrossRef] [PubMed]

19. Yasuoka, J.; Nanishi, K.; Kikuchi, K.; Suzuki, S.; Ly, P.; Thavrin, B.; Omatsu, T.; Mizutani, T. Barriers for pregnant women living in rural, agricultural villages to accessing antenatal care in Cambodia: A community-based cross-sectional study combined with a geographic information system. PLoS ONE 2018, 13, e0194103. [CrossRef] [PubMed]

20. Matsuoka, S.; Aiga, H.; Rasmey, L.C.; Rathavy, T.; Okitsu, A. Perceived barriers to utilization of maternal health services in rural Cambodia. Health Policy 2010, 95, 255-263. [CrossRef] [PubMed]

21. Moore, N.; Blouin, B.; Razuri, H.; Casapia, M.; Gyorkos, T.W. Determinants of first trimester attendance at antenatal care clinics in the Amazon region of Peru: A case-control study. PLoS ONE 2017, 12, e0171136. [CrossRef] [PubMed]

22. Kisuule, I.; Kaye, D.K.; Najjuka, F.; Ssematimba, S.K.; Arinda, A.; Nakitende, G.; Otim, L. Timing and reasons for coming late for the first antenatal care visit by pregnant women at Mulago hospital, Kampala Uganda. BMC Pregnancy Childbirth 2013, 13, 121. [CrossRef]

23. Andrew, E.V.; Pell, C.; Angwin, A.; Auwun, A.; Daniels, J.; Mueller, I.; Phuanukoonnon, S.; Pool, R. Factors affecting attendance at and timing of formal antenatal care: Results from a qualitative study in Madang, Papua new guinea. PLoS ONE 2014, 9, e93025. [CrossRef]

24. Kadobera, D.; Sartorius, B.; Masanja, H.; Mathew, A.; Waiswa, P. The effect of distance to formal health facility on childhood mortality in rural Tanzania, 2005-2007. Glob. Health Action 2012, 5, 19099. [CrossRef] 
25. Simon, P.C. A simple technique for mass cultivation of campylobacter fetus. Can. J. Comp. Med. 1976, 40, 318-319.

26. Siedner, M.J.; Lankowski, A.; Tsai, A.C.; Muzoora, C.; Martin, J.N.; Hunt, P.W.; Haberer, J.E.; Bangsberg, D.R. GPS-measured distance to clinic, but not self-reported transportation factors, are associated with missed HIV clinic visits in rural Uganda. AIDS 2013, 27, 1503-1508. [CrossRef] [PubMed]

27. Feikin, D.R.; Nguyen, L.M.; Adazu, K.; Ombok, M.; Audi, A.; Slutsker, L.; Lindblade, K.A. The impact of distance of residence from a peripheral health facility on pediatric health Utilisation in rural western Kenya. Trop. Med. Int. Health 2009, 14, 54-61. [CrossRef] [PubMed]

28. Peng, Y.M.; Deng, D.D.; Shi, F.; Tian, Y.W.; Chen, Y.R. Analysis on vision screening among preschool children aged 4-6 years old in Huairou District of Beijing City, 2017. Chin. J. Health Educ. 2018, 34, 163-165. (In Chinese)

29. World Health Organization. Available online: http://www.who.int/mediacentre/factsheets/fs300/zh/ (accessed on 28 November 2018).

30. CHINADAILY. Available online: http://www.chinadaily.com.cn/dfpd/2010-03/17/content_9602931.htm (accessed on 28 November 2018).

31. CSDH. Closing the Gap in a Generation: Health Equity through Action on the Social Determinants of Health; Final Report of the Commission on Social Determinants of Health; World Health Organization: Geneva, Switzerland, 2008.

32. De Santiago, A.X.; Barreto, I.C.; Sucupira, A.C.; Lima, J.W.; de Andrade, L.O. Equitable access to health services for children aged 5 to 9 in a medium city of northeasth of brazil: A result of family health strategy. Rev. Braz. J. Epidemiol. 2014, 17 (Suppl. 2), 39-52. [CrossRef]

33. Modi, D.; Gopalan, R.; Shah, S.; Venkatraman, S.; Desai, G.; Desai, S.; Shah, P. Development and formative evaluation of an innovative Mhealth intervention for improving coverage of community-based maternal, newborn and child health services in rural areas of India. Glob. Health Action 2015, 8, 26769. [CrossRef] [PubMed]

34. Tobe, R.G.; Haque, S.E.; Ikegami, K.; Mori, R. Mobile-health tool to improve maternal and neonatal health care in Bangladesh: A cluster randomized controlled trial. BMC Pregnancy Childbirth 2018, 18, 102. [CrossRef] [PubMed] 